\title{
THE STRUCTURAL AND PARAMETRICAL ORGANIZATION OF ELEMENTS OF A POWER SUPPLY SYSTEM IN THE CONDITIONS OF NETWORK CENTRISM
}

\begin{abstract}
Purpose. Development of indicators of the structural and parametrical organization of effective active and adaptive system of service of power supply systems in the conditions of ideology of Smart Grid. Methodology. In the conditions of application of ideology of Smart Grid for increase of intellectualization of electrical power system there is a need of introduction of the principle of a network centrism in the structural and parametrical organization of elements of power supply systems that involves performance of conditions on implementation of provisions of the principle of Situational Awareness. The essence of this principle consists in that, information on a condition of system has to be presented in the form convenient for the analysis, recognition, transfer, distribution and storage, to be coordinated for flexible and optimum development at the subsystem and object-by-object levels. Results. Structural and parametrical optimization of elements of power supply systems in the conditions of a network centrism and the concept of $S G$ involves use of provisions of the theory of systems and concepts of multicriteria optimizing synthesis. It is offered to use the modified adaptive indicator of the generalizing effect of synthesis of structure of active and adaptive system of service of power supply systems in the form of a difference of the generalizing effects: the introduced option of structure of system and basic. Originality. Introduction of an adaptive indicator of synthesis of system of service of power supply systems considers the concept of "service of system on the basis of a response" in the presence of false and true refusals. Practical value. Use of the specified indicator will allow to specify procedure of selection of competitive options for the purpose of definition of a set of admissible structures which meet the requirements of criterion function. References 9. Key words: Smart Grid, network-centric control system, active and adaptive system of service of power supply systems, productive actual response.
\end{abstract}

В статье рассмотрены тенденции развития и принципы организации интеллектуальных энергосистем при введении понятия сетецентризма в условиях идеологии Smart Grid. В качестве решения задач указанной проблематики предлагается создание активно-адаптивной системы, реализующей концепцию «обслуживания системы на основе отклика». Библ. 9.

Ключевые слова: Smart Grid, сетецентрическая система управления, активно-адаптивная система обслуживания энергосистем, результативный фактический отклик.

Introduction and problem definition. In the electric power system of the world and Ukraine is not the first year they are working on the «intellectualization of networks» - Smart Grid (SG). Currently, the ideology of building of intellectual energy networks the SG [1] (a term is introduced by Michael T. Burr in 2003 [2] - one of the most significant and developed at the modernization of the global energy industry. In the US and Western Europe, a number of large and more smallscale projects for the transition of power industry as well as housing and utilities to "smart grids» SG [3] are realized. Fundamentally new approaches are such in which the leading role is assigned to the kernel of the power system - the electrical network as a structure to ensure effectiveness of connection of the generation and consumer.

At the same time there is still no comprehensive concept of the formation of structural-parametric grid elements and the organization of information and intellectual bases of increase of efficiency of management technologies based on the SG.

Analysis of recent investigations and publications. Backgrounds of world community interest in the idea of SG concept are clear: growing indicators of resource consumption, increasing the cost of electricity production, the existing network of energy supplies rapidly respond to fluctuations in the economic sphere.

With the increasing demands of the international community used the production model and the delivery of energy resources cease to be satisfactory; for example, the current amount of electricity losses in networks of Ukraine is more than $25 \%$ [4]. These and other factors are pushing the government and power generating enterprises of various countries for the speedy implementation of the principles of SG concept.

In general, a power supply networks, developing the concept as part of SG, you can make the following demands: adaptability, efficiency, accessibility and opportunity for feedback, safety, information security, complexity and integration functions SG [5].

At the moment, the most acute problem of power systems as an element of the Ukrainian electricity system in order to increase energy efficiency and reduce prices for consumers.

The goal of investigations is development of indicators of structural and parametric organization of effective active-adaptive service system of power systems in a Smart Grid ideology.

Main research materials. Currently, there is the evolution of energy systems - from the simplest forms, using basic networking technologies in the energy sector, to more complex forms within SG network-centric concept with elements of nature, which are based on the latest generation of Internet technologies and implement a model of energy activities.

The concept of network centrism means building and maintaining up to date common to the whole image of the real situation of the system in the most clear and simple form. Usage information field should allow to (C) E.I. Sokol, O.G. Gryb, S.V. Shvets 
perceive the whole image of the system as a whole at this time interval based on the system response to ongoing changes in its status under the influence of various factors.

The successful solution of management tasks within the framework of network-centric approach is to maintain this image in the most complete and reliable and able to implement the provisions of Situational Awareness principle [6] (integrated complex perception and analysis for the benefit of a single system).

The existing information infrastructure in Ukraine with its traditional practice justified solutions of information and communication problems in the difficult conditions of the territorial, technical and natural-climatic nature, it requires new approaches, taking into account the need to meet the challenges of the country's transition to an innovative path of development.

It is necessary to consider and use the new principles of active-adaptive power system on the basis of networkcentric concept. The main of them is the use of all types of information, the development of traditional and new sources of information, based on the principles of adaptive structural-parametric elements of the organization of energy systems; improving the quality, safety and reliability of data collection, processing, storage and distribution of information.

The current stage of technology adoption in the SG grid of Ukraine is characterized by dependence on the processes of formation of «smart grids» of foreign technology solutions. The reason is the lack of clearly expressed in a network of information-analytical and expert-analytical support of the Ukrainian economy, namely:

- technical, organizational and legal problems of collection and processing of expert information used for management decision-making [7];

- lagging behind in the implementation of modern information tools and strategic-level control systems in the power industry [8].

When considering the performance characteristics of energy systems it is often necessary to carry out repair and maintenance works. With the introduction of the network centrism provisions it is proposed to use the concept of "service system on the basis of response» (SSR). This concept allows to increase the possibility of repair units of high-voltage transmission lines and substations for their application not distributed objects. The introduction of the SSR concept is aimed at servicing specific object (digital substation, power lines, power system status monitoring subsystem elements, etc.), located in a particular area and at a particular time, and which currently require maintenance in accordance with the response of the system. In this connection, it is possible to reduce the total number of units involved by virtue of their pitting and more efficient operation.

For real network-centric management system there are no obstacles in the number of units on the scale of action to restore the operating condition of high-voltage lines and digital substations. There are only obstacles to the effectiveness of the repair teams, that is, the ability of the selected outfit of forces and means to execute with reasonable efficiency the appointed time restore operability constituent element of the power system.

To build an effective active-adaptive power system's maintenance system (PSMS), built on the principles of network centrism it is necessary that it should based on the supremacy of communication systems, allowing real-time to receive and transmit information packets huge variety of customers, including centralized and distributed transmission. The PSMS of specified control type should be based on thorough preparation of the composition of repair crews, exploiting the system. Such an approach would greatly reduce the staff and reallocate responsibilities of team members to perform peculiar to their office tasks.

As one of the main elements of the proposed PSMS an unmanned aerial vehicle - UAV (quadrocopter, multicopter, hexacopter, etc) can act [9]. UAV operation mode is determined by the list of PSMS performed tasks within the main tasks of the power system. Among them - the control of the operator of the current events on the power system objects, control of repair when restoring a high-voltage lines, control of compliance with the requirements of labor protection and work with high voltage, remote control supply voltage after the recovery cycle uptime grid on the relevant sections of high-voltage lines, etc.

The problem of synthesis of PSMS in general formulation involves the use of a systematic approach. It is proposed to solve this problem apply the general indicator of the effectiveness of the selection options PSMS structure of the system, using the concept of the SSR.

The general formulation of the synthesis problem is as follows:

$$
\begin{aligned}
& W=\max \left\{O E_{v}(x)-O E_{b}(x)\right\}, \quad \text { at } \quad x \in X ; \\
& C_{n z} \rightarrow \min ,
\end{aligned}
$$

where $O E_{v}(x)$ is the summarizing effect of the implementation of the introduced version of the PSMS; $O E_{b}(x)$ is the summarizing effect of the implementation of the basic variant of the structure of the PSMS; $X$ is the feasible region; $C_{n z}$ are non-productive expenditures.

This index is constructed as the difference between generalizing effects: the introduced version of the PSMS system structure and base one.

The expression for the generalizing effect of synthesized PSMS structure will look like:

$$
\begin{gathered}
O E_{v}(x)=\left(\sum_{i=1}^{n} P_{i} P_{c i} P_{w w i} k_{g i}\left(R O_{f i}-C_{i}\right) \times\right. \\
\left.\times \prod_{j=1}^{k} \exp \left(-\left\{\lambda_{q i j}+\lambda_{c i j}\right\} t_{p i j}\right)\right)-C_{d},
\end{gathered}
$$

where $P_{i}$ is the apriori probability requirement to perform the corresponding subsystem of the $i$-th problem; $P_{c i}$ is the probability that it will not disrupt the implementation of the $i$-th problem due to lack of operational subsystem; $P_{w w i}$ is the probability that it will not disrupt the implementation of the $i$-th problem of setting the $i$-th by 
subsystem defective mean; $\kappa_{g i}$ is the availability of the $i$-th subsystem; $R O_{f i}$ is the actual cost value of the effective response in the performance of the $i$-th problem; $C_{i}$ are the costs associated with the implementation of the selected option maintenance subsystem for the $i$-th subsystem and the measurement of parameters of the subsystem during operation; $\lambda_{q i j}, \lambda_{c i j}$ are the intensities of sensible and latent failures of the $j$-th component of the $i$-th subsystem; $t_{p i j}$ is the time during which the explicit and latent failures are examined; $C_{d}$ are costs associated with the operation of the system of the PSMS.

Using the concept of the SSR for the PSMS system expressions for $R O_{f i}$ and $C_{i}$ will be the following:

$$
\begin{aligned}
& R O_{f i}=R O_{b i}+R O_{c i} ; \\
& C_{i}=C_{b i}+C_{c i},
\end{aligned}
$$

where $R O_{b i}$ and $C_{b i}$ is absolute value terms the effective response of the actual costs and, depending on the decision of the $i$-th problem by the corresponding subsystem; $R O_{c i}$ and $C_{c i}$ is the actual cost value effective response and costs arising from the introduction of the concept of the SSR.

In general, for the steady operation mode of the system of the PSMS:

$$
\begin{aligned}
& R O_{b i}=\sum_{j=1}^{m} P_{i j} \sum_{k=1}^{m} P_{i j k} R O_{i j k} ; \\
& C_{b i}=\sum_{j=1}^{m} P_{i j} \sum_{k=1}^{m} P_{i j k} C_{i j k},
\end{aligned}
$$

where $P_{i j}$ is the probability of finding of the $i$-th subsystem in each of $j$-th states during operation; $R O_{i j k}$, $C_{i j k}$ is the actual cost value of effective response and costs derived from the proper use of the $i$-th subsystem in the transition from from the state $j$ to the state $k ; P_{i j k}$ is the probability of transition of $i$-th subsystem from the state $j$ to the state $k$ in the process of solving the current problems.

Values of $R O_{c i}$ and $C_{c i}$ are described by expressions:

$$
\begin{aligned}
R O_{c i} & =\sum_{j=1}^{Z} P_{i j}\left(R O_{c p i j}\left(t_{s i j}\right)\right) P_{i j}\left(t_{s i j}\right) P O_{c p b i j}\left(t_{s i j}\right) ; \\
C_{c i} & =\sum_{j=1}^{Z} P_{i j}\left(C_{c p i j}\left(t_{s i j}\right)\right) P_{i j}\left(t_{s i j}\right) C_{c p b i j}\left(t_{s i j}\right),
\end{aligned}
$$

where $R O_{c p i j}\left(t_{s i j}\right)$ and $C_{c p i j}\left(t_{s i j}\right)$ are the components of effective response and actual costs of the $j$-th component of the $i$-th subsystem for $t_{s i j}$-th service time; $R O_{c p b i j}\left(t_{s i j}\right)$ and $C_{c p b i j}\left(t_{s i j}\right)$ are the unconditional effective components of the actual response and costs of the $j$-th component of the $i$-th subsystem for $t_{s i j}$-th service time.

Values of $R O_{i j k}$ and $C_{i j k}$ will be determined by random matrices of discrete values of the size of the system in steady state operation of the PSMS:

$$
\left[R O_{i j k}\right]=\left[\begin{array}{cccc}
R O_{i 11} & R O_{i 12} & \ldots & R O_{i 1 k} \\
R O_{i 21} & R O_{i 22} & \ldots & R O_{i 2 k} \\
\ldots \ldots \ldots & \ldots \\
R O_{i k 1} & R O_{i k 2} & \ldots & R O_{i k k}
\end{array}\right]
$$

Values of $R O_{c p i j}\left(t_{s i j}\right)$ and $C_{c p i j}\left(t_{s i j}\right)$ are described by matrices, similar expressions (6). The values of these matrices are chosen for the corresponding time $t_{s i j}$.

In the operation of the PSMS system there are situations when the $j$-th component of the $i$-th subsystem can be on service, not take into account the nature of the SSR concept, depending on the reliability of the means used, which leads to the presence of components $R O_{c p i j}\left(t_{s i j}\right)$ and $C_{c p i j}\left(t_{s i j}\right)$. These components are also described by matrices of the type (6).

Taking into account the expressions (2) - (5), and taking into account that the components of $R O_{i j k}, C_{i j k}$, $R O_{c p i j}\left(t_{s i j}\right), C_{c p i j}\left(t_{s i j}\right)$ are described by expressions of the type (6), we obtain an expression of adaptive index summarizing the synthesis effect of PSMS structure, which has been modified for the SSR concept:

$$
\begin{aligned}
& O E_{v}=\sum_{i=1}^{n} P_{i} k_{g i} \times \prod_{j=1}^{N}\left(1-\left(\beta_{i j}+\left(1-\beta_{i j}\right) P_{1 i j}\right)\right) \times \\
& \left.\times\left(\frac{1-P_{2 i j}}{P_{1 i j}\left(P_{1 i j}+P_{2 i j}\right.}\right)\right) \times\left[\sum_{j=1}^{L} P_{i j} \times \sum_{k=1}^{M} P_{i j k}\left(R O_{i j k}-C_{i j k}\right)+\right. \\
& +\sum_{j=1}^{Z}\left\{P_{i j}\left(R O_{c p i j}\left(t_{s i j}\right)\right) P_{i j}\left(t_{s i j}\right) R O_{c p b i j}\left(t_{s i j}\right)-\right. \\
& \left.\left.-P_{i j}\left(C_{c p i j}\left(t_{s i j}\right)\right) P_{i j}\left(t_{s i j}\right) C_{c p b i j}\left(t_{s i j}\right)\right\}\right] \times \\
& \times \prod_{j=1}^{V} \exp \left(-\left(\lambda_{q i j}+\lambda_{c i j}\right) t_{p i j}\right)-\left(P_{u}\left(C_{u}+\left(K_{p}+E\right) K+C_{m}\right)\right),
\end{aligned}
$$

where $\beta_{i j}$ is the probability of latent failure of the $j$-th components of the $i$-th subsystem; $P_{1 i j}$ is the probability of finding of the $j$-th components of the $i$-th subsystem in good and working condition; $P_{2 i j}$ is the probability of finding the $j$-th component of the $i$-th subsystem in use with a latent failure; $P_{u}$ is the probability of the adoption of the system of the PSMS in operation; $C_{u}$ are the current annual costs of operating of the system of the PSMS; $K_{p}$ is the rate of renovation of components of the system of the PSMS; $K$ is the regulatory cost-effectiveness ratio; $E$ are non-recurring costs during commissioning of the PSMS system operation; $P_{i j}\left(t_{s i j}\right)$ is the probability of service of the $i$-th subsystem of duration $t_{s i j}$ because of false or latent failures; $C_{m}$ is the payroll staff fund.

Conclusions. In the conditions of application of «Smart Grid - opportunities» to improve the intellectualization of the Ukrainian electricity system with active-adaptive power supply network there is a need to introduce the principle of network centrism in structuralparametric organization of the elements of energy systems. This optimization of the elements of power systems under conditions of network centrism and SG concept involves the use of the theory of systems and the concepts of multi-criteria optimization synthesis. The proposed modification of the adaptive index summarizing the effect of synthesis of the PSMS structure that takes into account the concept of the SSR in the presence of false and true bounce, will clarify the competitive options selection process to determine the set of possible structures that meet the requirements of the target synthesis function. 
1. SMART

\section{REFERENCES}

http://www.oe.energy.gov/smartgrid.htm

Available

at:

(Accessed 12 May 2014).

2. Michael T. Burr. Technology corridor: Reliability demands will drive automation. Fortnightly Magazine, 2003, November 1. Available at: http://www.fortnightly.com/fortnightly/2003/11/ technology-corridor?page $=0 \% 2 \mathrm{C} 0$ (Accessed 15 June 2004).

3. Dorofeyev V.V. Intellectual network. New principles of construction. The equipment and control systems of an intellectual network. Report at a meeting of a round table on the subject "Clever Networks - Clever Power - Clever Economy», Saint Petersburg, 2010. Available at: http://www.fskees.ru/media/File/press_centre/speeches/Presentation_dorofeev. pdf. (Rus).

4. Bykova O., Ablyazov P. Where the power industry moves? Available at: http://www.bigpowernews.ru/research/document 47671 (Accessed 24 November 2015). (Rus).

5. 10 trends of the SMART Grid market in 2012. Available at http://www .cleandex.ru/articles/2012/08/23/10_trendov_rynka _smart_grid_v_ssha (Accessed 02 April 2013). (Rus).

6. Mica R. Endsley, Daniel J. Garland. Situation Awareness Analysis and Measurement. Lawrence Erlbaum Associates, Inc., Mahwah, NJ, 2000. 383 p. ISBN 08058-2134-1.

7. Network examination. $2^{\text {nd }}$ prod. Edited by D.A. Novikov, A.N. Raykov. Moscow, Egves Publ., 2011. 166 p. (Rus).
8. Kosyanchuk T.F. Diagnosis of the competitive potential of the company. Scientific notes. Series «Economy», 2013, no.23, pp. 51-54. (Ukr).

9. Available at: http://quadrocopter.ua/quadrocopters copters (Accessed 11 July 2015).

Received 05.02.2016

E.I. Sokol ${ }^{1}$, Doctor of Technical Science, Professor,

Corresponding Member of the National Academy of Science of Ukraine,

O.G. Gryb ${ }^{1}$, Doctor of Technical Science, Professor,

S.V. Shvets ${ }^{2}$, Candidate of Technical Science, Associate

Professor,

${ }^{1}$ National Technical University «Kharkiv Polytechnic Institute», 21, Frunze Str., Kharkiv, 61002, Ukraine.

${ }^{2}$ O.M. Beketov National University of Urban Economy in Kharkiv,

17, Marshal Bazhanov Str., Kharkiv, 61002, Ukraine, phone+38067 7680838, e-mail: se_sx@bk.ru

How to cite this article:

Sokol E.I., Gryb O.G., Shvets S.V. The structural and parametrical organization of elements of a power supply system in the conditions of network centrism. Electrical engineering \& electromechanics, 2016, no.2, pp. 61-64. doi: 10.20998/2074-272X.2016.2.11. 